DOI: https://doi.org/10.24127/ajpm.v10i2.3574

\title{
E-MODUL MATEMATIKA BERBASIS SANTUN BERBAHASA BAGI SISWA SLOW LEARNER
}

\author{
Savitri Wanabuliandari $^{1^{*}}$, Ristiyani ${ }^{2}$, Nuning Kurniasih ${ }^{3}$ \\ ${ }^{1,2}$ Universitas Muria Kudus, Indonesia \\ ${ }^{3}$ Universitas Padjajaran, Indonesia \\ *Corresponding author. \\ E-mail: $\quad$ savitri.wanabuliandari@umk.ac.id $^{\left.{ }^{*}\right)}$ \\ ristiyani@umk.ac.id ${ }^{2)}$ \\ $\underline{\text { nuning.kurniasih@unpad.ac.id }}^{3)}$
}

Received 18 February 2021; Received in revised form 21 June 2021; Accepted 27 July 2021

\begin{abstract}
Abstrak
Tujuan dari penelitian ini adalah (1) menganalisis kelayakan e-modul matematika berbasis santun berbahasa dari ahli materi, ahli bahasa, dan ahli media pembelajaran. Jenis penelitian yang digunakan dalam penelitian ini adalah penelitian pengembangan. Model pengembangan menggunakan desain dari Borg dan Gall. Saat ini penelitian berada pada tahap validasi ahli. Modul divalidasi oleh tiga validator yaitu ahli materi, ahli bahasa, dan ahli media pembelajaran. Teknik pengumpulan data dengan menggunakan instrumen penilaian produk oleh para ahli. Instrumen yang dipakai menggunakan lembar penilaian produk yang berisi lembar penilaian dan saran para ahli. Penilaian dari ahli materi terdiri dari tiga aspek yaitu aspek kelayakan Isi, aspek kelayakan penyajian dan aspek penilaian kontekstual. Penilaian dari ahli bahasa terdiri dari dua aspek yaitu aspek kelayakan kebahasaan, dan aspek santun berbahasa. Penilaian dari ahli media pembelajaran terdiri dari tiga aspek yaitu aspek kelayakan kegrafisan Modul, aspek perangkat lunak, dan aspek komunikasi visual. Hasil validasi yang didapatkan adalah ahli materi pada kategori sangat layak, ahli bahasa pada kategori sangat layak, dan ahli media pembelajaran pada kategori layak. Jadi E-modul Matematika Berbasis Santun Berbahasa layak untuk digunakan ke tahap berikutnya.
\end{abstract}

Kata kunci: e-modul matematika, santun berbahasa, slow learner, validasi ahli

\begin{abstract}
The objectives of this research are (1) to analyze the e-module mathematics based on the language skills of the material experts, linguists, and media experts learning. This type of research used in this research is development research. The development model uses designs from Borg and Gall. Currently the research is at the expert validation stage. The module was validated by three validators, namely material experts, linguists, and learning media experts. Data collection techniques using product assessment instruments by experts. The instrument used is a product assessment sheet which contains an assessment sheet and expert advice. The material expert's assessment consists of three aspects, namely content feasibility aspects, presentation feasibility aspects and contextual assessment aspects. The assessment of the linguist consists of two aspects, namely the aspect of linguistic feasibility, and the polite aspect of language. The assessment of learning media experts consists of three aspects, namely aspects of the feasibility of the module's graphics, software aspects, and aspects of visual communication. The validation results obtained are material experts in the very feasible category, language experts in the very feasible category, and learning media experts in the appropriate category. So the E-module of Mathematics Based on Polite Language is worthy to be used to the next stage.
\end{abstract}

Keywords: expert validation, math e-module; polite language, slow learner

This is an open access article under the Creative Commons Attribution 4.0 International License 
DOI: https://doi.org/10.24127/ajpm.v10i2.3574

\section{PENDAHULUAN}

Salah satu siswa yang membutuhkan bahan ajar sendiri adalah siswa slow learner. (Rosmawati, 2017) siswa slow learner memiliki kecerdasan dibawah siswa pada umumnya tetapi mereka bukan tidak pintar akan tetapi butuh usaha lebih dalam mempelajari materi pelajaran. (Wanabuliandari et al., 2020) Siswa slow learner membutuhkan belajar berulang-ulang supaya mencapai tujuan pembelajaran. Permasalahan yang sering siswa slow learner adalah (1) penggunaan kosa kata yang minim (2) sulit memahami yang bersifat abstrak, (3) butuh waktu untuk mengulang materi, (4) motivasi belajar kurang. (Cahdriyana \& Setyorini, 2019) gejala yang menunjukkan keterlambatan belajar adalah percaya diri rendah, memiliki sifat pemalu, sering tidak nyaman dengan kondisi sekitarnya. (Turi et al., 2017) kendala yang dihadapi siswa slow learner dalam pembelajaran adalah pemahaman terhadap masalah kurang, ragu dengan jawabannya sehingga sering dihapus jika mengerjakan soal, tidak suka tantangan, kosakata yang kurang sehingga kesulitan menyampaikan keinginannya, dan lambat merespon ketika guru bertanya. Ini menunjukkan bahwa siswa slow learner memiliki kendala dalam memahami materi pelajaran di sekolah.

Salah satu mata pelajaran yang sering ditakuti siswa slow learner adalah matematika. (Wanabuliandari, S., \& Purwaningrum, 2018) slow learner memiliki kendala dalam belajar matematika. Hal ini karena matematika bersifat abstrak dan banyak menggunkan simbol-simbol, sehingga menjadi kendala bagi siswa slow learner untuk mempelajari matematika. (Supriadi, 2015) pembelajaran matematika sulit untuk karena banyak menggunakan simbol yang bersifat abstrak. (Febriana et al., 2017) menyebut bahwa siswa slow learner membutuhkan pemahaman berulang dalam belajar matematika dan tidak dapat diajak lebih dalam memahami materi matematika. (Putri et al., 2013) menyebut bahwa matematika merupakan ilmu yang penting dalam keseharian, dikarenakan matematika dapat membantu dalam memecahkan berbagai persoalan. Oleh karena itu, guru perlu mengetahui lebih dalam karakteristik siswa slow learner agar pembelajaran lebih maksimal.

Agar pembelajaran lebih maksimal guru juga harus mengetahui penggunaan bahasa yang santun. (Kurniasih et al., 2020) belajar bahasa yang santun ketika pembelajaran matematika merupakan hal yang penting, karena membantu siswa mengurangi rasa takutnya. Hasil ini sesuai dengan hasil wawancara dengan siswa slow learner yang menyebutkan bahwa guru kadang menakut-nakuti mereka, atau mengeluarkan kalimat negatif yang membuat mereka semakin takut untuk belajar matematika. (Wanabuliandari \& Ristiyani, 2019) pemahaman siswa dapat maksimal dengan diiringi kalimat yang santun. Oleh karena itu, untuk menunjang penggunaan bahasa yang santun, guru dan siswa slow learner perlu dibekali dengan sumber belajar yang mendukung terlaksananya hal tersebut.

Berdasarkan hasil studi lapangan ditemukan bahwa bahan ajar yang digunakan adalah buku paket dari pemerintah, siswa juga menggunakan LKS dari penerbit, guru belum mengembangkan bahan ajar sendiri, serta bahan ajar yang digunakan oleh siswa belum memuat materi yang dikaitkan dengan kondisi lingkungan sekitar. Sedangkan hasil wawancara 
dengan guru menunjukkan bahan ajar yang selama ini digunakan belum menyajikan materi pembelajaran sesuai dengan kondisi lingkungan yang ada di daerah, dan guru kesulitan saat mencoba mengkaitkan materi dengan contoh yang ada di lingkungan sekitar. Hal ini menunjukkan bahwa guru belum mengembangkan bahan ajar yang sesuai dengan kebutuhan siswa.

Sumber belajar yang dapat membekali bahasa yang santun dapat berupa bahan ajar berbentuk modul. (Lestari \& Andriani, 2019) menyebut bahwa modul merupakan bahan ajar yang disusun agar siswa dapat belajar secara mandiri. (Rufii, 2015) modul merupakan pembelajaran yang yang disusun secara terstuktur untuk menemukan pengalaman belajar secara mandiri dengan kriteria pembelajaran yang jelas serta koheren dan mempunyai kiteria dalam menilai yang jelas. (Sipayung \& Simanjuntak, 2017) modul disusun secara sistematis dan menarik agar siswa mudah mempelajari secara mandiri. (Ekayanti, 2017) dengan mempelajari modul siswa dapat belajar sesuai dengan kecepatannya. Pengembangan modul perlu disiasati dengan perkembangan teknologi. Koloborasi ini sering dikenal dengan sebutan e-modul. Melalui pengembangan e-modul ini dapat membantu siswa untuk belajar dimana saja dan kapanpun dengan biaya relatif terjangkau. E-modul ini dapat membantu guru dalam mengajarkan materi serta membantu siswa mengukur kemampuannya secara mandiri.

Dalam penelitian ini, dikembangkan e-modul matematika berbasis santun berbahasa. Melalui emodul matematika ini dapat membantu siswa slow learner untuk belajar matematika secara terstuktur dan mandiri. Dalam pengembangannya juga dilengkapi dengan penggunaan bahasa yang santun disetiap kalimatnya. Hal ini, untuk melatih berbahasa dan menambah kosakata siswa slow learner menjadi lebih santun. Serta membantu guru untuk memahami kalimat apa saja yang boleh diucapkan ketika berkomunikasi dengan siswa slow learner. Melalui komunikasi yang baik akan meningkatkan motivasi belajar siswa slow learner. Melalui pengembangan e-modul matematika berbasis santun berbahasa dapat membantu siswa slow learner dan guru selama pembelajaran matematika.

Selain itu, siswa dapat meningkatkan motivasinya yang berujung pada peningkatan pemahaman terhadap materi. Berdasarkan hasil kajian pustaka terdahulu seperti yang dilakukan oleh (Buchori \& Rahmawati, 2017) berjudul Pengembangan E-Modul Geometri dengan Pendekatan Matematika Realistik di Sekolah Dasar belum mengolaborasikan modul, teknologi, dan kesantunan berbahasa. Buchori hanya sebatas mengembangkan modul dan digital nejadi E-modul. Penelitian lain dilakukan oleh (Feriyanti et al., 2019) berjudul Pengembangan Emodul Matematika untuk Siswa SD. Penelitian Feriyanti, dkk. belum memuat kesantunan berbahasa dalam merancang e-modul matematika untuk siswa SD. Berdasarkan beberapa kajian pustaka sebelumnya, maka perlu melakukan penelitian analisis validasi ahli E-modul Matematika berbasis Kesantunan Berbahasa untuk Siswa Slow learner di sekolah dasar. Namun e-modul matematika berbasis santun berbahasa belum melalui uji kelayakan. Oleh karena itu, perlu dilakukan penelitian terkait uji kelayakan dari emodul matematika berbasis santun berbahasa yang sudah dikembangkan. 


\section{METODE PENELITIAN}

Jenis penelitian yang digunakan dalam penelitian ini adalah penelitian pengembangan. Model pengembangan menggunakan desain dari (Borg \& Gall, 1983) dengan modifikasi. Tahapan yang dilaksanakan meliputi tahap perencanaan, tahap pengembangan, dan tahap evaluasi. Pada tahap pengembangan e-modul matematika berbasis santun berbahasa melaksakan kegiatan validasi produk oleh ahli. Validasi e-modul matematika berbasis santun berbahasa dilakukan untuk mengetahui apakah e-modul matematika berbasis santun berbahasa yang disusun layak untuk digunakan sebagai bahan ajar siswa. Modul divalidasi oleh tiga validator yaitu ahli materi, ahli bahasa, dan ahli media pembelajaran.

Validasi modul dilaksanakan oleh tiga validator ahli. Validator ahli materi Dhina Cahya Rohim dari Universitas Muhamaddiyah Kudus. Validator bahasa Alfian Rokhmansyah dari Universitas Mulawarman. Validator media pembelajaran yaitu Alif Catur Murti dari Universitas Muria Kudus.

Teknik pengumpulan data dengan instrumen penilaian produk oleh para ahli. Instrumen yang digunakan dalam pengumpulan data menggunakan lembar penilaian produk yang berisi lembar penilaian dan saran para ahli. penilaian dari ahli materi terdiri dari tiga aspek yaitu aspek kelayakan Isi, aspek kelayakan penyajian dan aspek penilaian kontekstual. Penilaian dari ahli bahasa terdiri dari dua aspek yaitu aspek kelayakan kebahasaan, dan aspek santun berbahasa. Penilaian dari ahli media pembelajaran terdiri dari tiga aspek yaitu aspek kelayakan kelayakan kegrafisan Modul, aspek perangkat lunak, dan aspek komunikasi visual.
Teknik analisis data menggunakan teknik analisis data kualitatif dan kuantitatif. Teknis analisis data kualitatif terdiri dari kritik maupun saran dari para ahli yang nantinya digunakan untuk perbaikan e-modul matematika berbasis santun berbahasa yang dikembangkan. Data kualitatif dari hasil validasi oleh ahli materi, bahasa, dan pembelajaran. Sedangkan analisis data kuantitatif terdiri dari hasil penilaian dari uji validasi yang dilakukan oleh para ahli yaitu ahli materi, bahasa, dan materi pembelajaran. Hasil penilaian ahli berupa skor yang berasal dari lembar validasi yang telah diberikan kepada para ahli. Pada Tabel 1 merupakan kategori kelayakan dari produk yang dikembangkan (Wanabuliandari, S., Ardianti, 2017).

Tabel 1. Kategori Kelayakan Modul

\begin{tabular}{cl}
\hline Interval & Kategori \\
\hline $\mathrm{Mi}+1,5 \mathrm{Sdi} \leq \mathrm{X} \leq \mathrm{Mi}+3 \mathrm{Sdi}$ & Sangat \\
& Layak \\
$\mathrm{Mi}+0 \mathrm{Sdi} \leq \mathrm{X}<\mathrm{Mi}+1,5 \mathrm{Sdi}$ & Layak \\
$\mathrm{Mi}-1,5 \mathrm{Sdi} \leq \mathrm{X}<\mathrm{Mi}+0 \mathrm{Sdi}$ & Cukup \\
& Layak \\
$\mathrm{Mi}-3 \mathrm{Sdi} \leq \mathrm{X}<\mathrm{Mi}-1,5 \mathrm{Sdi}$ & Tidak \\
& Layak \\
\hline
\end{tabular}

Keterangan :

$\mathrm{X}$ : Skor

Mi : mean Ideal $\quad\left(\frac{1}{2}\right.$ (skor tertinggi + skor terendah))

Sdi : Standar deviasi ideal $\left(\frac{1}{6}\right.$ (skor tertinggi - skor terendah)

Kriteria kelayakan e-modul matematika berbasis santun berbahasa digunakan sebagai dasar dalam melakukan penilaian terhadap kelayakan e-modul matematika berbasis santun berbahasa. Modul yang dikembangkan dapat digunakan jika terletak pada kategori layak atau sangat layak. 


\section{HASIL DAN PEMBAHASAN}

Salah satu tahapan pengembangan bahan ajar modul dalam bentuk elektronik untuk mengetahui E-modul tersebut layak atau tidak untuk digunakan dalam proses pembelajaran adalah uji validasi ahli (Ramadhani \& Fitri, 2020). Uji validasi bertujuan mengukur kelayakan E-modul sebelum digunakan dalam proses pembelajaran. Dalam proses uji validasi akan memeroleh saran dan masukan untuk perbaikan E-modul agar siap digunakan.

Setelah melaksanakan pengembangan aplikasi e-modul matematika berbasis santun berbahasa langkah selanjutnya adalah tahap validasi. Produk yang telah dikembangakan kemudia di validasikan kepada ahli untuk dievaluasi dan mendapatkan beberapa masukan guna perbaikan modul. Tahap validasi modul juga dilakukan untuk mengetahui apakah modul yang disusun layak untuk digunakan sebagai bahan ajar siswa. Modul divalidasi oleh tiga validator yaitu ahli materi, ahli bahasa, dan ahli media pembelajaran.

Penilaian dilakukan oleh ahli materi, bahasa, dan media pembelajaran. penilaian dari ahli materi terdiri dari tiga aspek yaitu aspek kelayakan Isi, aspek kelayakan penyajian dan aspek penilaian kontekstual. Penilaian dari ahli bahasa terdiri dari dua aspek yaitu aspek kelayakan kebahasaan, dan aspek santun berbahasa. Penilaian dari ahli media pembelajaran terdiri dari tiga aspek yaitu aspek kelayakan kelayakan kegrafisan Modul, aspek perangkat lunak, dan aspek komunikasi visual.

Penentuan kategori kelayakan modul terdiri dari 4 kategori yaitu sangat layak, layak, cukup layak, serta tidak layak (Fatmawati et al., 2018)

\section{Analisis Validasi oleh Ahli Materi}

Penyusunan materi pada mata pelajaran matematika harus memperhatikan kaakteristik siswa dalam hal ini siswa slow learner. Untuk itu, pengembangan materi modul perlu di validasi agar dapat membantu siswa slow learner memahami materi. Penentuan interval dan kategori kelayakan e-modul matematika berbasis santun berbahasa dari ahli materi mengacu pada Tabel 1. Berikut ini kategori kelayakan E-modul Matematika Berbasis Santun Berbahasa dari ahli materi dapat dilihat pada Tabel 2.

Tabel 2. Kategori kelayakan e-modul matematika berbasis santun berbahasa dari ahli materi

\begin{tabular}{cc}
\hline Interval Skor & Kategori \\
\hline $97,5 \leq$ Skor $\leq 120$ & Sangat Layak \\
$75 \leq$ Skor $<97,5$ & Layak \\
$52,5 \leq$ Skor $<75$ & Cukup Layak \\
$30 \leq$ Skor $<52,5$ & Tidak Layak \\
\hline \multicolumn{2}{c}{ Penilaian Validasi ahli materi }
\end{tabular}
terdiri dari aspek kelayakan isi, kelayakan penyajian, dan penilaian kontekstual. Hasil penilaian pada setiap aspek oleh ahli materi ditunjukkan pada Tabel 3.

Tabel 3. Hasil penilaian setiap aspek oleh ahli materi

\begin{tabular}{lcccc}
\hline \multicolumn{1}{c}{ Aspek } & Skor Maksimal & $\begin{array}{c}\text { Skor } \\
\text { Penilaian }\end{array}$ & Total Skor & Kategori \\
\hline Kelayakan Isi & 48 & 45 & 111 & Sangat \\
Kelayakan Penyajian & 36 & 32 & & Layak \\
Penilaian Kontekstual & 36 & 34 & & \\
\hline
\end{tabular}


DOI: https://doi.org/10.24127/ajpm.v10i2.3574

Berdasarkan Tabel 3, penilaian dari ahli materi terdiri dari tiga aspek yaitu aspek kelayakan Isi, aspek kelayakan penyajian dan aspek penilaian kontekstual. Pada aspek kelayakan isi hasil penilaian menunjukkan skor 45. Isi e-modul sudah sesuai dengan kebutuhan belajar dan kesesuaian isi materi dengan silabus kurikulum 2013. Struktur modul sebagai bahan ajar sebaiknya dibuat sesuai dengan tuntutan kurikulum dan kebutuhan siswa (Fajarini et al., 2016).

Pada aspek kelayakan penyajian hasil penilaian menunjukkan skor 32 . Hal ini menunjukkan bahwa penyajian e-modul matematika berbasis santun berbahasa sudah sesuai dengan kebutuhan siswa slow learner. E-modul matematika berbasis santun berbahasa juga disusun secara sistematis dan menarik siswa. Penyajian materi juga ditampilkan melalui ilustrasui gambar.

Pada aspek penilaian kontektual hasil penilaian menunjukkan skor 34 . Hal ini menunjukkan bahwa konten emodul matematika berbasis santun berbahasa berkaitan dengan kehidupan sehari-hari siswa slow learner. Melalui konten yang berkaitan dengan kehidupan sehari-hari siswa slow learner dapat membantu dalam memahami materi. Hal ini senada dengan (Nilasari et al., 2016) yang menjelaskan bahwa pembelajaran matematika yang berdasarkan pengalaman siswa dalam kehidupan sehari-hari akan membantu siswa memahami materi matematika yang bersifat abstrak.

Berdasarkan hasil penilaian pada setiap aspek oleh ahli materi menunjukkan kategori sangat layak. Hal ini menunjukkan bahwa konsep materi, contoh soal, pemberian latihan soal yang terdapat dalam e-modul matematika berbasis santun berbahasa sesuai dengan pembelajaran pada kurikulum 2013 dan disesuaikan dengan kebutuhan siswa slow learner. (Sudaryono et al., 2013) menyebutkan bahwa dalam pembelajaran kurikulum 2013 pada konsep teori, contoh kasus, pemberian latihan soal harus menyesuaikan kurikulum yang ada.

\section{Analisis Validasi oleh Ahli Bahasa}

Kelayakan modul pembelajaran merupakan kepantasan suatu modul untuk digunakan dalam proses pembelajaran setelah mendapatkan penilaian dari pakar untuk diujikan langsung pada siswa (Utaminingsih, 2017). Selain uji validitas ahli materi perlu dilakukan uji validasi ahli bahasa. Uji validasi ahli bahasa bertujuan untuk menilai kelayakan penggunaan bahasa dalam modul untuk siswa SD.

(Wanabuliandari et al., 2020) menyebutkan bahwa penggunaan bahasa yang santun pada siswa slow learner penting. Mengingat siswa slow learner memiliki emosi yang labil. Dengan menggunakan bahasa yang santun siswa slow learner akan merasakan kenyamanan belajar. Oleh karena itu dalam penyusunan modul juga perlu divalidasi dulu dalam penggunaan bahasanya, sudah santun atau belum. Penentuan interval dan kategori kelayakan e-modul matematika berbasis santun berbahasa dari ahli bahasa mengacu pada Tabel 1 . Kategori kelayakan e-modul matematika berbasis santun berbahasa dari ahli bahasa dapat dilihat pada Tabel 4.

Tabel 4. Kategori kelayakan e-modul matematika berbasis santun berbahasa dari ahli bahasa

\begin{tabular}{cc}
\hline Interval Skor & Kategori \\
\hline $35,75 \leq$ Skor $\leq 44$ & Sangat Layak \\
$27,5 \leq$ Skor $<35,75$ & Layak \\
$19,25 \leq$ Skor $<27,5$ & Cukup Layak \\
$11 \leq$ Skor $<19,25$ & Tidak Layak \\
\hline
\end{tabular}


DOI: https://doi.org/10.24127/ajpm.v10i2.3574

Sedangkan hasil yang didapatkan dari penilaian setiap aspek oleh ahli bahasa menunjukkan hasil pada Tabel 5.

Tabel 5. Hasil penilaian setiap aspek oleh ahli bahasa

\begin{tabular}{ccccc}
\hline Aspek & $\begin{array}{c}\text { Skor } \\
\text { Maksimal }\end{array}$ & $\begin{array}{c}\text { Skor } \\
\text { Penilaian }\end{array}$ & $\begin{array}{c}\text { Total } \\
\text { Skor }\end{array}$ & Kategori \\
\hline Kelayakan Kebahasaan & 36 & 33 & 40 & Sangat Layak \\
Santun Berbahasa & 8 & 7 & & \\
\hline
\end{tabular}

Berdasarkan Tabel 5 penilaian dari ahli bahasa terdiri dari dua aspek yaitu aspek kelayakan kebahasaan, dan aspek santun berbahasa. Pada aspek kelayakan kebahasaan hasil penilaian menunjukkan skor 33. Pada aspek kelayakan santun berbahasa hasil penilaian menunjukkan skor 7 . Ini berarti hasil penilaian setiap aspek oleh ahli bahasa menunjukkan kategori sangat layak. Hal ini menunjukkan bahwa e-modul matematika berbasis santun berbahasa disusun menggunakan bahasa yang mudah dipahami siswa slow learner, santun dan komunikatif. Hal ini sejalan dengan (Muslich, 2010) salah satu ciri bahan ajar yang baik yakni menggunakan bahasa yang komunikatif sehingga siswa lebih mudah dalam memahami konten bahan ajar. Bahasa yang santun atau positif akan membantu guru untuk memahami karakteristik siswa (Gilang et al., 2018). Sehingga e-modul matematika berbasis santun berbahasa sangat layak dari segi ahli bahasa.

Analisis Validasi oleh Ahli Media Pembelajaran

(Ekayanti, 2017) menjelaskan bahwa modul yang baik adalah modul yang desainnya menarik serta mudah digunakan. Dengan memperhatikan detail dari modul maupun e-modul harapannya siswa slow learner menjadi tertarik dalam pembelajaran. Penentuan interval dan kategori kelayakan e-modul matematika berbasis santun berbahasa dari ahli bahasa mengacu pada Tabel 1 . Sedangkan kategori kelayakan E-modul Matematika Berbasis Santun Berbahasa dari ahli bahasa dapat dilihat pada Tabel 6.

Tabel 6. Kategori kelayakan e-modul matematika berbasis santun berbahasa dari ahli media pembelajaran

\begin{tabular}{cl}
\hline Interval Skor & Kategori \\
\hline $123,5 \leq$ Skor $\leq 152$ & Sangat Layak \\
$95 \leq$ Skor $<123,5$ & Layak \\
$66,5 \leq$ Skor $<95$ & Cukup Layak \\
$38 \leq$ Skor $<66,5$ & Tidak Layak \\
\hline \multicolumn{2}{c}{ Hasil penilaian setiap aspek oleh } \\
ahli media pembelajaran ditunjukkan \\
pada Tabel 7.
\end{tabular}

Tabel 7. Hasil penilaian setiap aspek oleh ahli media pembelajaran

\begin{tabular}{lcccc}
\hline \multicolumn{1}{c}{ Aspek } & Skor Maksimal & $\begin{array}{c}\text { Skor } \\
\text { Penilaian }\end{array}$ & $\begin{array}{c}\text { Total } \\
\text { Skor }\end{array}$ & Kategori \\
\hline Kelayakan & 108 & 86 & 122 & Layak \\
Kegrafisan Modul & 12 & 10 & & \\
Perangkat Lunak & 32 & 26 & & \\
Komunikasi Visual & 32 & & \\
\hline
\end{tabular}

Berdasarkan Tabel 7 penilaian dari ahli media pembelajaran terdiri dari tiga aspek yaitu aspek kelayakan kelayakan kegrafisan Modul, aspek 
perangkat lunak, dan aspek komunikasi visual. Pada aspek kelayakan kegrafisan modul hasil penilaian menunjukkan skor 86. Pada aspek perangkat lunak hasil penilaian menunjukkan skor 10 . Pada aspek komunikasi visual hasil penilaian menunjukkan skor 26. Ini berarti hasil penilaian setiap aspek oleh ahli media pembelajaran pada kategori layak.

Tingginya tingkat kevalidan ahli media menunjukkan bahwa e-modul matematika berbasis santun berbahasa didesain dengan tampilan yang menarik, tata letak penulisan yang menarik dan emodul mudah digunakan. E-modul matematika berbasis santun berbahasa yang didesain dengan warna-warna yang cerah, tata letak penulisan yang menarik dan gambar yang mendukung materi dapat membuat siswa tertarik untuk belajar matematika (Mudiono et al., 2017; Yasa et al., 2017). Media pembelajaran yang baik adalah media pembelajaran yang jelas dan rapi dalam tampilannya dan berkualitas baik pada setiap aspeknya. Oleh karena itu, dari segi ahli media pembelajaran e-modul matematika berbasis santun berbahasa dikategorikan layak.

Dari Tabel 3, hasil validasi ahli materi menunjukkan skor 111 dari total skor 120. Berdasarkan hasil skor tersebut menurut ahli materi, E-modul Matematika Berbasis Santun Berbahasa termasuk pada kategori sangat layak. Berdasarkan tabel 5, hasil validasi ahli bahasa menunjukkan skor 40 dari total skor 44. hasil validasi ahli bahasa menunjukkan bahwa E-modul Matematika Berbasis Santun Berbahasa pada kategori sangat layak. Sedangkan hasil validasi ahli media pembelajaran pada tabel 7, menunjukkan bahwa Emodul Matematika Berbasis Santun Berbahasa mendapat skor 122 dari total skor 152. Hasil validasi ahli media pembelajaran tersebut menunjukkan bahwa E-modul Matematika Berbasis Santun Berbahasa pada kategori layak. Oleh karena itu, berdasarkan penilaian ahli e-modul matematika berbasis santun berbahasa layak untuk digunakan pada tahap selanjutnya.

\section{Rekapitulasi hasil analisis validasi ahli}

Rekapitulasi hasil penilaian oleh validator ditunjukkan pada Tabel 8 .

Tabel 8. Rekapitulasi hasil validasi oleh ahli

\begin{tabular}{|c|c|c|}
\hline Penilaian & $\begin{array}{c}\text { Skor } \\
\text { Penilaian }\end{array}$ & Kategori \\
\hline Ahli Materi & 111 & $\begin{array}{l}\text { Sangat } \\
\text { Layak }\end{array}$ \\
\hline Ahli Bahasa & 40 & $\begin{array}{l}\text { Sangat } \\
\text { Layak }\end{array}$ \\
\hline $\begin{array}{l}\text { Ahli Media } \\
\text { Pembelajaran }\end{array}$ & 122 & Layak \\
\hline
\end{tabular}

$\begin{array}{cccr}\text { Hal } & \text { ini } & \text { berarti } & \text { berdasarkan } \\ \text { penilaian } & \text { dari } & \text { ketiga } & \text { validator }\end{array}$ menunjukkan hasil yang berbeda. Hasil yang ditunjukkan adalah ahli materi pada kategori sangat layak, ahli bahasa pada kategori sangat layak, dan ahli media pembelajaran pada kategori layak. Hasil kesimpulan validasi dari ahli materi adalah E-modul Matematika Berbasis Santun Berbahasa dapat digunakan tanpa revisi. Sedangkan hasil kesimpulan validasi ahli bahasa adalah E-modul Matematika Berbasis Santun Berbahasa dapat digunakan dengan revisi. Hasil kesimpulan validasi ahli media pembelajaran adalah E-modul Matematika Berbasis Santun Berbahasa dapat digunakan dengan revisi.

Selain melakukan penilaian terhadap modul, para ahli juga memberikan beberapa masukan dan saran. Masukan dan saran dari ahli kemudian digunakan sebagai bahan perbaikan e-modul matematika berbasis 
santun berbahasa. Penilaian dari validator materi adalah Modul dapat digunakan untuk membantu siswa slow learner, modul memiliki kelebihan pada materi yang berkaitan dengan kehidupan sehari-hari. Sedangkan saran dari validator materi adalah Opsi pada soal pilihan ganda lebih baik ditulis satu kolom untuk memudahkan siswa dalam mengerjakan.

Penilaian dari validator bahasa adalah Modul sangat membantu siswa slow learner, modul mempunyai kelebihan pada penggunaan bahasa yang santun yang tidak dimiliki oleh modul lain. Saran dari validator bahasa adalah Menggunakan ilustrasi yang mencerminkan kesantuanan, misalnya gambar anak yang berjabat tangan dengan teman, atau menunduk kepada orang tua.disesuaikan dengan materi perbabnya, dan dalam perintah soal sudah menggunakan bahasa yang santun akan tetapi yang materi masih belum banyak memuat kalimat yang santun. Sedangkan penilaian dari validator media pembelajaran adalah Modul membantu siswa slow learner karena didukung oleh visual yang baik, modul bisa tersampaikan dengan baik dengan tampilan (huruf dan ilustrasi) yang menarik. Saran dari validator media pembelajaran adalah Pada bagian sampul warna lebih kontras, pada bagian evaluasi terkait dengan soal yang muncul lebih baik bisa ditampilkan random (urutan berubah ketika siswa mencoba untuk melakukan evaluasi), tampilan pada menu guruterutama bagian tambah siswa harus dibuat lebih kontras (supaya terlihat sebagai menu, bukan sebagai keterangan), terkait dalam segi keamanan aplikasi ini belum menerapkan session sehingga ketika sudah logout masih bisa kembali kehalaman sebelumnya (belum benarbenar logout). Berdasarkan penilaian dan saran dari ketiga validator maka peneliti melakukan revisi untuk mendapatkan produk yang siap digunakan untuk uji skala terbatas.

Tahap validasi dilakukan dengan membagikan lembar validasi modul kepada 3 validator. Validator memberikan penilaian terhadap e-modul matematika berbasis santun berbahasa. Dari masukan para ahli tersebut kemudian dijadikan dasar untuk mememperbaiki e-modul matematika berbasis santun berbahasa sesuai dengan saran para ahli. Akhirnya didapatkan emodul matematika berbasis santun berbahasa pada kategori yang sangat layak dan layak.

Kelayakan E-modul berdasarkan hasil rekapitulasi di atas merupakan kepantasan E-modul untuk digunakan dalam proses pembelajaran agar siswa lebih antusias dalam belajar matematika dan rasa takut dengan matematika berkurang. Selaras dengan yang disampaikan (Utaminingsih, 2017) dari hasil uji ahli yang diperoleh digunakan sebagai landasan untuk mengembangkan modul matematika ke tahap selanjutnya. Hasil uji validasi ahli terhadap E-modul Matematika Berbasis Santun Berbahasa pada Siswa Slow learner ini juga sejalan dengan penelitian (Buchori \& Rahmawati, 2017); (Feriyanti et al., 2019); (Violadini \& Mustika, 2021).

\section{KESIMPULAN DAN SARAN}

Hasil kesimpulan validasi ahli menunjukkan bahwa penilaian ahli materi dan bahasa pada kategori sangat layak, penilaian ahli media pembelajaran pada kategori layak sehingga e-modul matematika berbasis santun berbahasa dapat digunakan tanpa revisi.

Saran dalam mengembangkan emodul matematika berbasis santun 
berbahasa yaitu mengetahui dahulu kebutuhan pengembangan e-modul matematika berbasis santun berbahasa ditinjau dari siswa slow learner dan guru, serta memperhatikan penggunaan bahasa santun dan keruntutan bahan materi yang dikembangkan.

\section{DAFTAR PUSTAKA}

Borg, W., \& Gall, M. (1983). Educational Research: An Introduction 4th edition Longman Inc. New York.

Buchori, A., \& Rahmawati, N. D. (2017). Pengembangan E-Modul Geometri dengan Pendekatan Matematika Realistik di Sekolah Dasa. Jurnal Sekolah Dasar, 26(1), 23-29. https://doi.org/10.17977/um009v26 i12017p023

Cahdriyana, R. A., \& Setyorini, R. (2019). Tingkat Kreativitas Slow learners Dalam Memecahkan Masalah Matematika. Kalamatika: Jurnal Pendidikan Matematika, 4(1), 1-14. https://doi.org/10.22236/kalamatik a.vol4no1.2019pp1-14

Ekayanti, A. (2017). Pengembangan Modul Irisan Kerucut Berbantuan Geogebra. AKSIOMA: Jurnal Program Studi Pendidikan Matematika, 6(3), 308-314. https://doi.org/10.24127/ajpm.v6i3. 1151

Fajarini, A., Soetjipto, B. E., \& Hanurawan, F. (2016). Developing A Social Studies Module by Using Problem Based Learning (PBL) With Scaffolding for the Seventh Grade Students in A Junior High School in Malang, Indonesia. IOSR Journal of Research \& Method in Education (IOSR-JRME), 6(1), 6269.
Fatmawati, L., Pratiwi, R. D., \& Erviana, V. Y. (2018). Pengembangan Modul Pendidikan Multikultural Berbasis Karakter Cinta Tanah Air dan Nasionalis pada Pembelajaran Tematik. Scholaria: Jurnal Pendidikan Dan Kebudayaan, 8(1), 80-92. https://doi.org/10.24246/j.js.2018.v 8.i1.p80-92

Febriana, R., Haryono, Y., \& Yusri, R. (2017). Effectiveness of Discovery Learning-Based Transformation Geometry Module. Journal of Physics: Conference Series, 1-5. https://doi.org/10.1088/17426596/895/1/012003

Feriyanti, N., Hidayat, S., \& Asmawati, L. (2019). Pengembangan EModul Matematika Untuk Siswa SD. JTPPm (Jurnal Teknologi Pendidikan dan Kebudayaan, 8(1), 41-50. https://doi.org/10.24246/ j.js.2018.v8.i1.p41-50

Kurniasih, N., Wanabuliandari, S., \& Ristiyani. (2020). Design of mathematical e-module based polite language for slow learners in primary schools. International Journal of Innovation, Creativity and Change.

Lestari, F., \& Andriani, D. G. (2019). Validasi modul berbasis literasi pada mata kuliah statistika matematika. Jurnal Math Educator Nusantara.

https://doi.org/10.29407/jmen.v5i0 1.12854

Mudiono, A., Akbar, S., Dwi Yasa, A., \& Delawanti Chrisyarani, D. (2017). Developing Multiple Intelligences-Based Thematic Comic Module. Pancaran Pendidikan, 6(4), 115-124. https://doi.org/10.25037/pancaran. v6i4.111

Muslich, M. (2010). Text Book Writing 
DOI: https://doi.org/10.24127/ajpm.v10i2.3574

Dasar-Dasar Pemahaman

Penulisan dan Pemakaian Buku Teks. Arruzz Media.

Nilasari, E., Djatmika, E., \& Santoso, A. (2016). Pengaruh Penggunaan Modul Pembelajaran Kontekstual Terhadap Hasil Belajar Siswa Kelas V Sekolah Dasar. Jurnal Pendidikan: Teori, Penelitian, Dan Pengembangan, 1(7), 1399-1404. https://doi.org/10.17977/jp.v1i7.65 83

Putri, I. A. P. G., Koyan, W., \& Candiasa, M. (2013). Pengembangan Tes Matematika Berbasis SK/KD dengan Teknik Concurent pada Siswa Kelas VI di SD Negeri Se Kecamatan Gianyar. E-Journal Program Pascasarjana Universitas Pendidikan Ganesha Program Studi Penelitian dan Evaluasi Pendidikan, 3, 1-14.

Ramadhani, R., \& Fitri, Y. (2020). Validitas E-Modul Matematika Berbasis EPUB3 Menggunakan Analisis Rasch Model. Jurnal Gantang, 5(2), 95-111. https://doi.org/10.31629/jg.v5i2.25 35

Rosmawati, R. (2017). Pengaruh antara Slow learner Terhadap Kesulitan Belajar Biologi MTs. BuLu-BuLu Kab Jeneponto. Universitas Islam Negeri Alauddin Makassar.

Rufii, R. (2015). Developing Module on Constructivist Learning Strategies to Promote Students' Independence and Performance. International Journal of Education, $\quad 7(1), \quad 18-28$. https://doi.org/10.5296/ije.v7i1.667 5

Sipayung, T. N., \& Simanjuntak, S. D. (2017). Efektivitas Pembelajaran Kooperatif Dengan Menggunakan Modul. AKSIOMA: Jurnal Program Studi Pendidikan
Matematika, 6(3), 393-398.

Sudaryono, Margono, G., \& Rahayu, W. (2013). Pengembangan Instrumen Penelitian Pendidikan. Graha Ilmu.

Supriadi, N. (2015). Pembelajaran Geometri Berbasis Geogebra Sebagai Upaya Meningkatkan Kemampuan Komunikasi Matematis Siswa Madrasah Tsanawiyah (MTs). Al-Jabar: Jurnal Pendidikan Matematika, 6(2), 99-109. https://doi.org/10.24042/ajpm.v6i2. 20

Turi, J. A., Ghani, M. F. A., Javid, Y., \& Sorooshian, S. (2017). Teacher's Instructional Strategies To Support Slow learners In Selected Schools, The Islamic Republic Of Pakistan Background And Introduction Of The Study. The Online Journal Of Islamic Education, 5(2), 10-19.

Utaminingsih, C. D. T. (2017). Pengembangan Modul Pembelajaran Matematika Dengan Menerapkan Pendekatan Saintifik Dalam Materi Pecahan Untuk Kelas 5 SD. Jurnal Mitra Pendidikan, 1(4), 408-419.

Violadini, R., \& Mustika, D. (2021). Pengembangan e-modul berbasis metode inkuiri pada pembelajaran tematik di sekolah dasar. Jurnal BASICEDU Journal of Elementary Education, 5(3), 1210-1222.

Wanabuliandari, S., \& Purwaningrum, J. P. (2018). Pembelajaran Matematika Berbasis Kearifan lokal Gusjigang Kudus Pada Siswa Slow learner. Eduma: Mathematics Education Learning And Teaching, 7(1), 63-70. http://syekhnurjati.ac.id/jurnal/inde x.php/eduma/article/view/2724 
DOI: https://doi.org/10.24127/ajpm.v10i2.3574

Wanabuliandari, S., Ardianti, D. S. (2017). Uji Kelayakan Modul Experiential Jelajah Alam Sekitar (EJAS) Berbasis Edutainment. Seminar Nasional IPA VIII Dengan Tema Inovasi Penelitian Dan Pembelajaran IPA Berwawasan Konservasi.

Wanabuliandari, S., \& Ristiyani, R. (2019). Program Hypnomathematics melalui KataKata Positif untuk Guru SD 4 Bae Kudus. Jurnal Pengabdian Pada Masyarakat, 4(3), 249-254. https://doi.org/10.30653/002.20194 3.150

Wanabuliandari, S., Ristiyani, R., \& Kurniasih, N. (2020). Desain Pengembangan Modul Matematika Berbasis Santun Berbahasa Untuk Siswa Slow learner Di Sekolah Dasar. AKSIOMA: Jurnal Program Studi Pendidikan Matematika. https://doi.org/10.24127/ajpm.v9i3. 2889

Yasa, A. D., Chrisyarani, D. D. S. A., \& Mudiono, A. (2017). Modul Komik Tematik Berbasis Multiple Intellegence Untuk Siswa Kelas V Sekolah Dasar. Sekolah Dasar: Kajian Teori Dan Praktik Pendidikan, 26(2), 175-181. 